\title{
The Ability of the FTC Method to Quantify Nicotine as a Function of Ammonia in Mainstream Smoke*
}

\author{
by \\ Charlene H. Callicutt ${ }^{l}$, Richard H. Cox ${ }^{l}$, Don Farthing ${ }^{l}$, Frank S. Hsu ${ }^{l}$, Lydia Johnson ${ }^{l}$, Susan Laffoon ${ }^{l}$, Peter Lee ${ }^{2}$, \\ Robin D. Kinser ${ }^{l}$, Kenneth F. Podrazal, Edward B. Sanders ${ }^{3}$, and Jeffrey I. Seeman ${ }^{1,4}$ \\ ${ }^{1}$ Philip Morris USA Research Center, 4201 Commerce Road, Richmond, Virginia 23234, USA. \\ ${ }^{2}$ P N Lee Statistics and Computing Ltd., Hamilton House, 17 Cedar Road, Sutton, Surrey SM2 5DA, England. \\ ${ }^{3}$ Philip Morris Products SA, CH-2003 Neuchâtel, Switzerland. \\ ${ }^{4}$ Current address: SaddlePoint Frontiers, 12001 Bollingbrook Place, Richmond, VA 23236, USA.
}

\section{SUMMARY}

Whether ammonia-forming ingredients added to tobacco and ammonia in smoke affect the ability of the Cambridge filter pad to trap nicotine in the Federal Trade Commission (FTC) method was examined. Three commercial cigarettes, two industry reference cigarettes, and four specially designed test cigarettes were used in this study to represent cigarettes with different construction and mainstream (MS) smoke yield characteristics. One of the commercial cigarettes, a US 1998 Marlboro Lights ${ }^{\circledR}$ King Size cigarette, was used as a control cigarette for the four experimental test cigarettes. The test cigarettes differed from the control cigarette as follows: first, a reduction in ammonia-forming ingredients added to the reconstituted tobaccos; second, no ammonia-forming ingredients added to the reconstituted tobacco; third, no ingredients at all added to the reconstituted tobaccos; and fourth, no ingredients at all added to the entire tobacco blend. An XAD-4 tube was placed downstream of the standard Cambridge filter pad in the FTC method to trap the gas-vapor phase nicotine for subsequent analysis. The Cambridge filter pad used in the FTC method was determined to provide greater than $99 \%$ trapping efficiency for MS smoke nicotine from cigarettes with widely different soluble ammonia levels in filler and MS smoke ammonia yields. [Beitr. Tabakforsch. Int. 22 (2006) 71-78]

\section{ZUSAMMENFASSUNG}

Es wurde untersucht, inwieweit sich bei der Methode der Federal Trade Commission (FTC) Ammoniak-bildende Substanzen, die dem Tabak hinzugefügt wurden sowie Ammoniak im Rauch auf die Fähigkeit der Cambridgefilter auswirken, Nikotin zurückzuhalten. Drei handelsübliche Zigarettenmarken, zwei industrielle Referenzzigaretten sowie vier speziell konzipierte Testzigaretten wurden in dieser Studie untersucht, um Zigaretten mit verschiedenen Konstruktionsmerkmalen und Werten bei den Hauptstromrauchbestandteilen zu berücksichtigen. Eine der Handelsmarken, eine US amerikanische Marlboro Lights ${ }^{\circledR}$ King Size Zigarette von 1998 diente als Kontrolle für die vier experimentellen Testzigaretten. Die Testzigaretten unterschieden sich von der Kontrollzigarette in folgenden Punkten: erstens, einer Verringerung der dem rekonstituierten Tabak hinzugefügten Ammoniak-bildenden Substanzen; zweitens, keine Hinzufügung Ammoniak-bildender Substanzen zum rekonstituierten Tabak; drittens, keine Hinzufügung irgendwelcher Substanzen zum rekonstituierten Tabak; viertens, keine Hinzufügung irgendwelcher Substanzen zur gesamten Tabakmischung. Um das Nikotin in der Gasphase zu untersuchen, wurde ein XAD-4 Röhrchen hinter dem standardmäßigen Cambridgefilter angebracht. Es wurde festgestellt, dass die Effizienz der bei der FTC Methode verwendeten Cambridefilter beim Auffangen von Nikotin im Hauptstromrauch von Zigaretten, die große Unterschiede im Gehalt an löslichem Ammoniak im Füllmaterial und den Ammoniakwerten im Hauptstromrauch aufwiesen, mehr als $99 \%$ betrug. [Beitr. Tabakforsch. Int. 22 (2006) 71-78]

\section{RESUME}

Dans cette étude il a été examiné si des composés producteurs d'ammoniac ajoutés au tabac et l'ammoniac dans la fumée pouvaient influencer la capacité des filtres Cambridge à piéger la nicotine selon la méthode normalisée de la Federal Trade Commission (FTC). Trois marques de cigarettes vendues dans le commerce, deux cigarettes 
industrielles de référence et quatre cigarettes d'essai spécialement conçues ont été examinées dans cette étude pour représenter des cigarettes ayant des propriétés de fabrication et des rendements en composants de la fumée du courant principal (CP) différents. Une des cigarettes commerciales, une cigarette US Marlboro Lights ${ }^{\circledR}$ King Size de l'année 1998 a été utilisée comme cigarette de référence pour les quatre cigarettes d'essai expérimentales. Les différences entre les cigarettes d'essai et la cigarette de référence sont les suivantes : premièrement, un apport réduit des composés producteurs d'ammoniac aux tabacs reconstitués ; deuxièmement, absence d'apport des composés producteurs d'ammoniac aux tabacs reconstitués ; troisièmement, absence d'apport d'aucun composé aux tabacs reconstitués ; quatrièmement, absence d'apport d'aucun composé au mélange du tabac. Selon la méthode normalisée FTC, un tube XAD-4 a été placé en aval du filtre Cambridge standard pour recueillir la nicotine de la phase vapeur pour une analyse ultérieure. L'étude a révélé que le filtre Cambridge utilisé dans la méthode FTC a une efficacité de piégeage de plus de $99 \%$ pour la nicotine du CP de cigarettes, et ceci pour les cigarettes ayant des teneurs très différentes en ammoniac soluble dans le tabac de remplissage et des rendements très différents en ammoniac dans le CP. [Beitr. Tabakforsch. Int. 22 (2006) 71-78]

\section{INTRODUCTION}

During the puffing of a cigarette, mainstream (MS) smoke aerosol is formed and issues from the mouth end of a cigarette. MS smoke is a dynamic aerosol, composed of particles and a gas phase. Some constituents of each phase are capable of chemical reactions as well as transferring from one phase to the other (1-4). MS smoke contains thousands of compounds having a wide range of concentration and structural variation (5-7). Well over 30 years ago, the US Federal Trade Commission (FTC), with the assistance of members of the tobacco industry, non-industry tobacco researchers, and the National Institutes of Health, developed standard methods to examine MS smoke constituents $(8,9)$. In the United States, MS smoke FTC nicotine (1) yield and FTC 'tar' yield are reported for commercial cigarettes, 'tar' being defined as total particulate matter (TPM) minus MS smoke water and nicotine content. A similar method used outside the United States (International Organization for Standardization, ISO) is also used to quantify machine-generated MS smoke nicotine and 'tar' yields $(10,11)$<smiles>CN1CCC[C@H]1c1cccnc1</smiles>

1

Cigarette manufacturers in the US are required to report FTC 'tar', nicotine and carbon monoxide yields, on a yearly basis, to the FTC using the standard FTC machine-smoking protocol. The FTC method allows the comparison of different cigarettes when smoked by a machine under identical laboratory conditions. Human smokers will obtain different amounts of nicotine and other smoke constituents depending on how they smoke the cigarettes $(12,13)$.

In the FTC method, a smoking machine generates one twosecond puff of $35 \mathrm{~mL}$ volume every minute until the butt length is at most $3 \mathrm{~mm}$ greater than the tipping paper length (8). The MS smoke is drawn through a Cambridge filter pad (CFP). Operationally, the material collected on the CFP is called the "total particulate matter" (TPM). The substances that pass through the CFP during all the puffs are called collectively "MS smoke gas-vapor phase" (2). It is possible that some material that passes through the CFP was originally trapped on the pad but evaporated from the pad in subsequent puffs or even within a single puff (14). During the past several years, attention has been drawn to the fact that in some countries, some cigarette manufacturers add ammonia-forming ingredients to the tobacco or to specific tobacco blend components in some of their commercial cigarettes (15-26). It has been hypothesized that the addition of ammonia-forming ingredients added to tobacco causes an under-quantification and an underreporting of FTC MS smoke nicotine using the FTC method $(13,25)$. BATES, JARVIS and CONNOLLY have proposed that "Changes in the state of nicotine from liquid or solid to gas would have the effect of evading the standard measuring process which records the residues left on the Cambridge filter in the standard smoking machine" (25). Underlying the claim that a significant quantity of MS smoke nicotine is not trapped by the Cambridge filter pad in the FTC method is the following hypothetical sequence: (1) that an increase in ammonia-forming ingredients added to tobacco can lead to an increase in MS smoke ammonia (27-30); (2) that an increase in MS smoke ammonia may result $(21,22,31)$ in an elevation in the amount of nicotine (1) in the gas phase of MS smoke; and (3) that gas-phase nicotine is not trapped by the Cambridge filter pad.

Recently, we have published a number of studies examining the effect of ammonia on the chemistry of nicotine in tobacco and smoke $(4,30-35)$. In this report, we determined the effectiveness of the FTC method to quantify total MS smoke nicotine yields using the Cambridge filter pad, over a range of brands and test cigarettes with a range of MS smoke ammonia levels comparable to those in commercial cigarettes. We find $>99 \%$ of MS smoke nicotine is trapped by the Cambridge filter pad and is quantified. Portions of this work were presented in preliminary fashion at two scientific meetings $(28,36)$.

\section{EXPERIMENTAL AND METHODOLOGY}

\section{Cigarettes}

The cigarettes tested consisted of two reference cigarettes (University of Kentucky 1R4F and Industry Monitor No. 16), three US commercial cigarettes, (Marlboro Lights ${ }^{\circledR}$ King Size, Cambridge ${ }^{\circledR}$ Lowest, and Merit Ultra Lights ${ }^{\circledR}$,) and four experimental cigarettes (T1-T4, see below). The Kentucky Reference 1R4F (production date January, 1983) (37) and Industry Monitor No. 16 (IM No. 16) (production date September, 1996) $(38,39)$, are commonly 
used as reference cigarettes and controls in analytical and smoke chemical studies. (The IM No. 17 cigarette is the currently used Industry Monitor cigarette.) The Kentucky Reference cigarettes and the Industry Monitor cigarettes can be obtained from the Kentucky Tobacco Research and Development Center (http://www.uky.edu/KTRDC/ research.html) and the Product Testing Laboratory, Philip Morris USA, 615 Maury Street, Richmond, VA 23224, respectively. As shown in Table 1, these nine cigarettes have a range of TPM yields from $2.0-21.9 \mathrm{mg} / \mathrm{cig}$, a range in soluble ammonia in tobacco from $0.831-2.27 \mathrm{mg} / \mathrm{cig}$, and a range in MS smoke ammonia from 1.57-16.6 $\mu \mathrm{g} / \mathrm{cig}$. Cigarettes T1-T4 were based on the Marlboro Lights ${ }^{\circledR}$ King Size and were designed to have similar TPM yields but significantly different soluble ammonia and MS smoke ammonia yields (see Table 1). This was achieved by reduction, in a stepwise fashion, of the levels of ammoniaforming ingredients and other ingredients such as processing aids, flavors and humectants (16) used in the manufacture of the control cigarette. This design protocol is shown in Table 2.

\section{Tobacco and smoke characteristics of the examined cigarettes}

Full experimental methods for all of the analyses reported herein except for the Cambridge filter trapping efficiency (see below) are reported elsewhere (30).

\section{Cambridge filter trapping efficiency}

The efficiency of the Cambridge filter pad $(44 \mathrm{~mm})$ for trapping nicotine was determined by smoking cigarettes on a Borgwaldt RM4/CS four-port linear smoking machine using the standard FTC machine-smoking conditions $(8,9)$. As shown in Figure 1, the material not trapped on the Cambridge filter was passed directly into an adsorbent tube containing an $80 \mathrm{mg}$ section of XAD-4 sorbent (SKC catalogue no. 226-93) followed by another $40 \mathrm{mg}$ section of XAD-4 sorbent. XAD-4 traps have been shown to be extremely effective at trapping nicotine in the gas phase (40-44). Immediately after the smoking, the Cambridge filter pad was placed in a pre-dried test tube $(18 \times 150 \mathrm{~mm}$, disposable, culture, borosilicate glass, part no. 14-961-32, Fisher Scientific, Pittsburgh, PA) with a sleeve stopper (part no. 16, West Company, Lionville, PA) where it remained until the analysis procedure. The XAD-4 material was extracted with $2 \mathrm{~mL}$ of 2-propanol containing $l$ carvone as an internal standard $(0.5 \mu \mathrm{g} / \mathrm{mL})$ and triethylamine $(0.02 \%, \mathrm{v} / \mathrm{v})$. The level of nicotine in the XAD-4 extract (injection volume: $1 \mu \mathrm{L}$ ) was analyzed by selective ion monitoring (SIM) GC-MS (ions $m / z$ 84, 133, 162) with both the limit of detection and limit of quantification in the parts per billion range.

\section{RESULTS AND DISCUSSION}

A series of cigarettes having a wide FTC TPM range (2-22 mg/cig), including cigarettes with multiple designs, was used to evaluate the capability of the Cambridge filter pad to trap MS smoke nicotine using the standard FTC machine-smoking method. The specific question of this study related to the possible role of ammonia in the trapping capability of the FTC method. The Marlboro Lights ${ }^{\circledR}$ King Size having a $13.0 \mathrm{mg} / \mathrm{cig}$ FTC TPM yield was chosen for the control because this represents an intermediate TPM yield found for US commercial cigarettes. As shown in Table 1, the Marlboro Lights ${ }^{\circledR}$ (the control, C) and T1-T4 have varying ammonia levels but similar FTC TPM yields.

The Cambridge filter pad collection efficiency of MS smoke nicotine was quantified for the cigarettes examined. The system shown in Figure 1 was designed to determine experimentally the fraction of nicotine that was not trapped and captured by the Cambridge filter pad. An XAD-4 trap was placed behind the Cambridge filter pad. XAD-4 is well-known to trap gas-phase nicotine with high efficiency (40-44). The Cambridge filter pad plus the XAD-4 system together provide an efficient collection mechanism for a composite of both particulate and gas-phase nicotine in smoke (40-47). This method cannot quantify or necessarily distinguish between the amounts of nicotine that are in the particulate or gas phase of MS smoke at the instant the smoke reaches the Cambridge filter pad, because breakthrough or re-volatilization of nicotine from the Cambridge filter pad is, in principle, possible. As shown in Figure 2, the TPM yields obtained using the XAD-4 trap were about $6 \%$ higher than the TPM yields found using the standard FTC method (data not given in Table 1). This difference may be the result of a slight difference in air pressure through the system when an XAD-4 backup trap is added to the FTC system. In any event, the highly significant correlation shown in Figure 2 demonstrates that the smoking process with an XAD-4 back-up tube is comparable to the standard FTC method.

The yields of nicotine on the Cambridge filter pad and on the XAD-4 back-up tube sorbent are shown in Table 1 . Nicotine on the XAD-4 sorbent back-up material indicates breakthrough of a small amount $(<0.0014 \mathrm{mg} / \mathrm{cig})$ of this tobacco alkaloid through the Cambridge filter pad. In all cases, $>99.2 \%$ of the total MS smoke nicotine on the Cambridge filter pad was detected and quantified, i.e., $<1 \%$ of the MS smoke nicotine was not trapped on the Cambridge filter pad but trapped on the XAD-4 sorbent.

Table 1 lists the MS smoke ammonia yields for the commercial Marlboro Lights ${ }^{\circledR}$ and for the four experimental cigarettes (T1-T4). This series, as indicated above, has very similar FTC 'tar' and nicotine yields but has a range of MS smoke ammonia yields (6-12 $\mu \mathrm{g} /$ cigarette) as well as progressive diminution in other ingredients and flavorants. Regardless of the amount of ammonia in MS smoke or the presence or absence of the added ingredients and flavorants, $>99.9 \%$ of the MS smoke nicotine for the Marlboro Lights $^{\circledR}$ and T1-T4 and $>99.2 \%$ of the MS smoke nicotine for the other cigarettes listed in Table 1 was trapped by the Cambridge filter pad. For the Marlboro Lights ${ }^{\circledR}$ and the four test cigarettes, there is no significant relationship $(p \geq 0.1)$ between the breakthrough of nicotine and either MS smoke ammonia $(r=-0.40)$ or soluble ammonia $(r=-0.29)$. Thus, greater than $99.9 \%$ of the MS smoke nicotine was trapped by the Cambridge filter pad and quantified in the FTC method for Marlboro Lights ${ }^{\circledR}$ and T1-T4, independent of the three following variables: the amount of soluble ammonia in the tobacco, TPM yields, and the amount of MS smoke ammonia. 


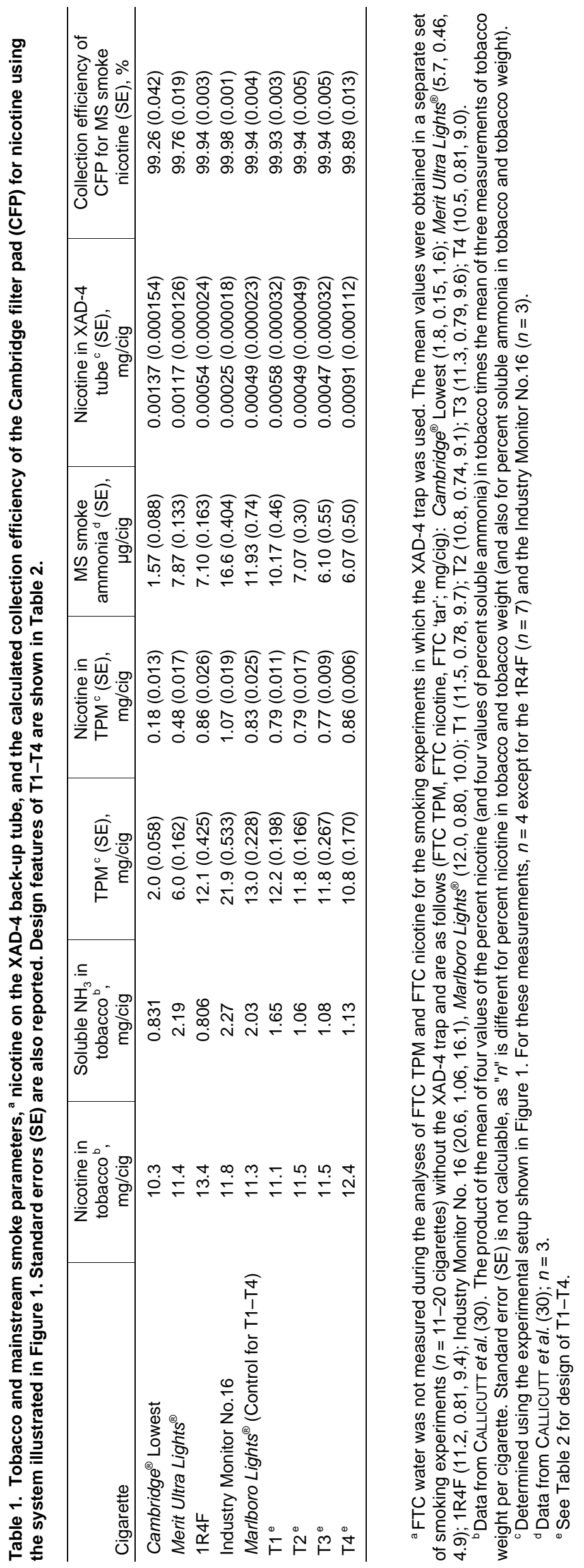


Table 2. Design characteristics of the tobacco blend for the 1998 US Marlboro Lights ${ }^{\circledR}$ cigarette (the control cigarette) and the four test cigarettes T1-T4.

\begin{tabular}{l|c|cc}
\hline Cigarette & $\begin{array}{c}\text { Ammonia-forming ingredients added to } \\
\text { reconstituted leaf in the cigarette blend }\end{array}$ & $\begin{array}{c}\text { Ingredients added to } \\
\text { reconstituted leaf }\end{array}$ & $\begin{array}{c}\text { Ingredients added to } \\
\text { tobacco blend }\end{array}$ \\
\hline Marlboro Lights ${ }^{\circledR}$ King Size & Yes & Yes & Yes \\
T1 & Reduced & Yes & Yes \\
T2 & No & Yes & Yes \\
T3 & No & No & Yes \\
T4 & No & No & No \\
\hline
\end{tabular}

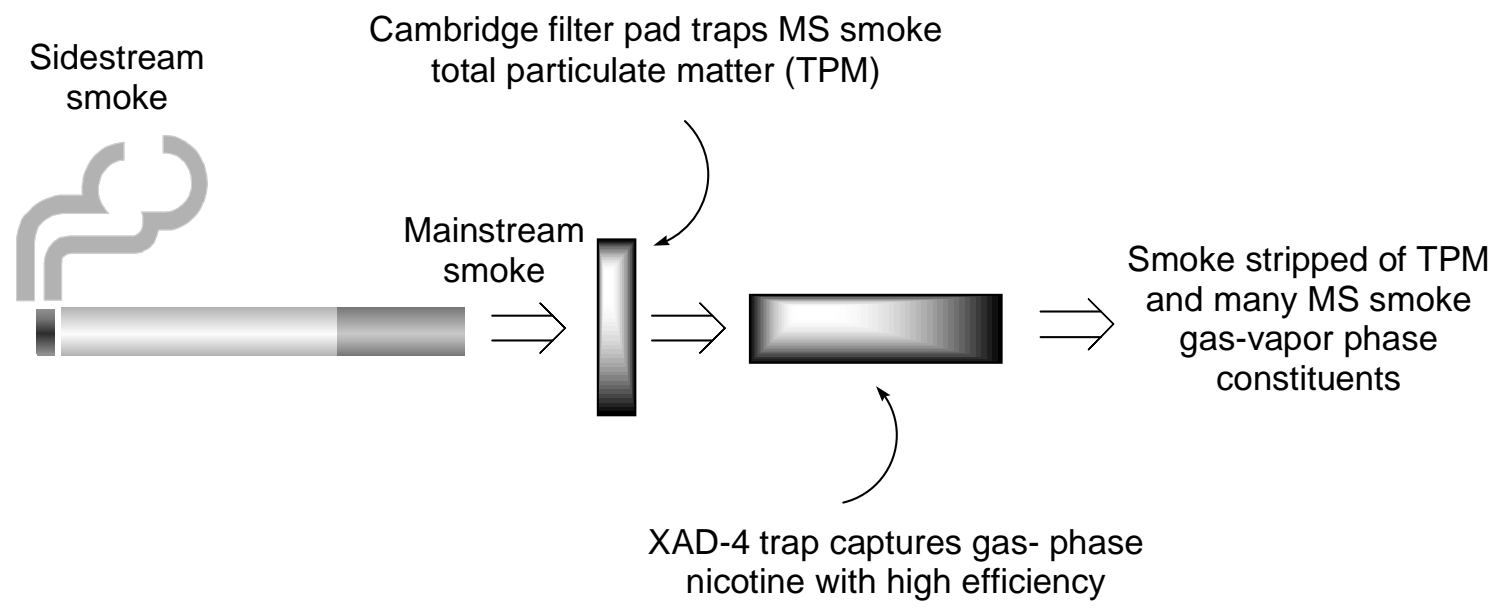

Figure 1. The FTC protocol was modified by the addition of an XAD-4 trap at the downstream side of the Cambridge filter pad. The XAD-4 trap is known to collect any nicotine that is not trapped by the Cambridge filter pad (see text for references and additional information)

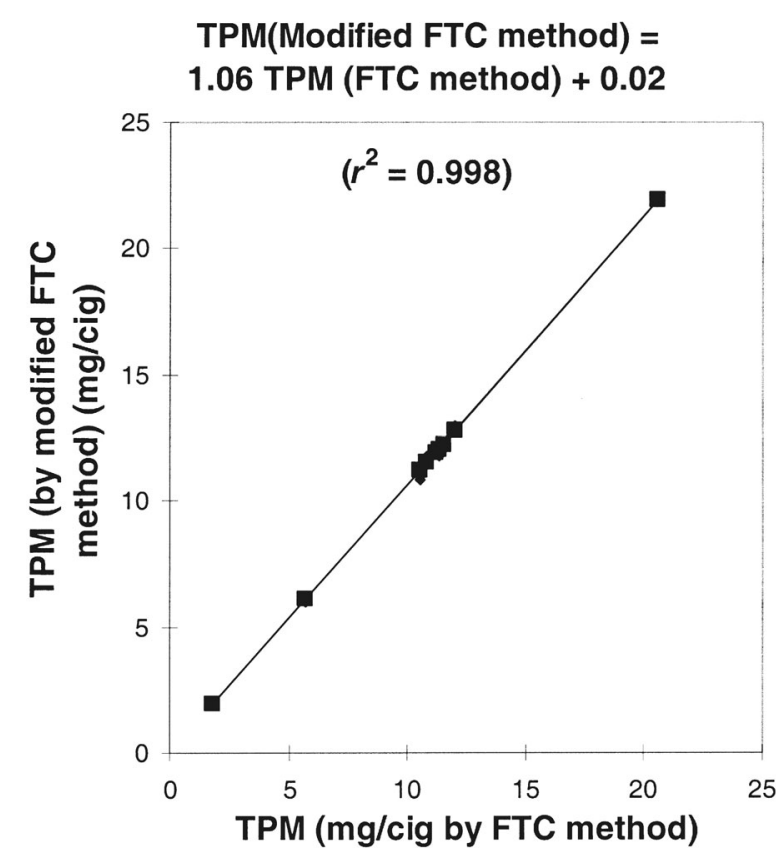

Figure 2. The correlation between the TPM yields obtained using the modified FTC method (XAD-4 trap method as shown in Figure 1) and the TPM yields using the standard FTC method for the nine cigarettes types described in Tables 1 and 2. A slope of near unity and a near zero intercept demonstrate that the incorporation of the XAD-4 filter had little effect on the total smoke formation.
It is instructive to examine the properties of the highest and lowest FTC 'tar' yield cigarettes in this study in order to identify any trends in the data. For the Cambridge ${ }^{\circledR}$ Lowest for which there was $2.0 \mathrm{mg} \mathrm{TPM} / \mathrm{cig}$ and $0.18 \mathrm{mg}$ nicotine/cig, $1.37 \mu \mathrm{g}$ nicotine (approximately $0.74 \%$ of the total MS smoke nicotine) was not trapped by the Cambridge filter pad. In contrast, Industry Monitor No.16 had $21.9 \mathrm{mg}$ $\mathrm{TPM} / \mathrm{cig}$ and $1.07 \mathrm{mg}$ nicotine/cig; $0.25 \mu \mathrm{g}$ nicotine (approximately $0.02 \%$ of the total MS smoke nicotine) was not trapped by the Cambridge filter pad. For the lowest FTC 'tar' yield cigarettes, a greater percentage of the nicotine was found on the XAD-4 tube (although in absolute mass, the nicotine in the XAD- 4 tube was very low, at $<1.4 \mu \mathrm{g} / \mathrm{cig}$ ). A modest though statistically significant correlation was found between the collection efficiency of the Cambridge filter pad and the FTC TPM yield $\left(r^{2}=0.62, p<0.012\right)$. At least two possibilities can be proposed for this observation. First, nicotine, water and other tobacco smoke constituents already trapped on a Cambridge filter pad could enhance the trapping of subsequent material reaching the pad. Second, material trapped on the pad could decrease the propensity of nicotine to transfer from the pad to the gas-vapor phase during subsequent puffs (48). BAKER has pointed out that temperature, filter loading, flow rate, and moisture level on the Cambridge filter pad can affect the pad's properties (2). Limited and somewhat inconsistent data is available on these possible effects (49-51). It is not possible at this time to distinguish between the two cited possible mechanisms based on the available data. 
Denuder tube experiments with fresh MS smoke (in the absence of a Cambridge filter pad) have demonstrated that nicotine is primarily in the particulate phase of MS smoke, that is, $<1 \%$ of nicotine is in the gas phase of MS smoke (21, $33,52-55)$. In addition, the Cambridge filter pad is $99.9 \%$ efficient for MS smoke particles that are larger than $0.1 \mu \mathrm{m}$ in diameter (2). Individual experiments with exogenouslyadded ${ }^{14} \mathrm{C}$-nicotine and exogenously-added ${ }^{2} \mathrm{H}$-nicotine indicate that $>99 \%$ of the nicotine in MS smoke is trapped on the Cambridge filter pad $(43,44,56)$. Following the completion of this work and its presentation at two scientific meetings $(28,36)$ and a meeting at the UK Department of Health in 2000, a report entitled "Determination of the Fate of Nicotine When a Cigarette is Smoked" was released by the Smoking Policy Unit, UK Department of Health (45). This report concluded that there was no evidence for nicotine passing through the Cambridge filter pad using the ISO protocol, and that the ISO machine smoking procedure accurately quantifies the yield of nicotine in MS smoke. In addition, a single experiment was recently reported in which a Carboxen/PDMS solid-phase microextraction fiber was placed behind the Cambridge filter pad and nicotine was not detected (57). Our experimental results (Table 1) and the literature data are fully consistent with each other. In total, all the experimental data strongly support the conclusion that the vast majority of the nicotine in MS smoke is retained on the Cambridge filter pad in the FTC and ISO machine-smoking methods and is quantified by standard analytical methods.

\section{CONCLUSION}

In this work, the proportion of MS smoke nicotine captured on the Cambridge filter pad in the FTC method was evaluated. An XAD-4 trap was placed downstream of and directly in series with the Cambridge filter pad to trap and allow quantification of MS smoke nicotine that passed through the Cambridge filter pad. Greater than $99 \%$ of the mainstream smoke nicotine was trapped on the Cambridge filter pad, for TPM yields ranging from $2-22 \mathrm{mg} / \mathrm{cig}$ and MS smoke ammonia yields ranging from 1.6-16.6 $\mu \mathrm{g} / \mathrm{cig}$. In addition, for the Marlboro Lights ${ }^{\circledR}$ and T1-T4 having nearly the same TPM yields (ca. $12 \mathrm{mg} / \mathrm{cig}$ ) but significantly different MS ammonia yields $(6-12 \mu \mathrm{g} / \mathrm{cig})$, the Cambridge filter pad trapped and the method quantified $>99.9 \%$ of the mainstream smoke nicotine. These results, in combination with literature reports, clearly demonstrate that $>99 \%$ of mainstream smoke nicotine is captured and quantified by the standard FTC and ISO machinesmoking methods for commercial conventional cigarettes.

\section{ACKNOWLEDGEMENTS}

The authors gratefully acknowledge the contributions of Dr. Cathy Ellis to study inception and design, data interpretation, and presentation. Portions of the work by Drs. Ellis and Jeffrey Seeman were performed as consultants to Philip Morris USA Inc. The authors thank members of the Philip Morris USA Product Testing Laboratory for providing analytical smoking data, Ronald Bassfield, Dr. R.W. Dwyer, Carla Gregory and Alan I. Goldsmith for technical assistance, and several reviewers for helpful comments and suggestions.

\section{REFERENCES}

1. Ingebrethsen, B.: The physical properties of main-stream cigarette smoke and their relationship to deposition in the respiratory tract; in: Extrapolation of dosimetric relationships for inhaled particles and gases, Academic Press, San Diego, 1989, pp 125-141.

2. Baker, R.: Smoke chemistry; in: Tobacco. Production, Chemistry and Technology, edited by D.L. Davis and M.T. Nielsen, Blackwell Science, Oxford, 1999.

3. Ingebrethsen, B. and C.S. Lyman: Particle formation and growth in gases from totally filtered mainstream cigarette smoke; Aerosol Sci. Tech. 36 (2002) 267-276.

4. Seeman, J.I., P.J. Lipowicz, J.-J. Piade, L. Poget, E.B. Sanders, J.P. Snyder, and C.G. Trowbridge: On the deposition of volatiles and semi-volatiles from cigarette smoke aerosols. The relative rates of transfer of nicotine and ammonia from particles to the gas phase; Chem. Res. Toxicol. 17 (2004) 1020-1037.

5. Stedman, R.L.: The chemical composition of tobacco and tobacco smoke; Chem. Rev. 68 (1968) 153-207.

6. Schmeltz, I. and D. Hoffmann: Nitrogen-containing compounds in tobacco and tobacco smoke; Chem. Rev. 77 (1977) 295-311.

7. Green, C.R. and A. Rodgman: The tobacco chemists' research conference: A half century forum for advances in analytical methodology of tobacco and its products; Recent Adv. Tob. Sci. 22 (1996) 131-304.

8. Pillsbury, H.C., C.C. Bright, K.J. O'Connor, and F.W. Irish: Tar and nicotine in cigarette smoke; J. Assoc. Official Anal. Chem. 52 (1969) 458-462.

9. Rodgman, A.: FTC "tar" and nicotine in mainstream smoke: A retrospective; Recent Adv. Tob. Sci. 23 (1997) 5-74.

10. ISO 3402: Determination of nicotine content in smoke condensates. Gas chromatographic method; International Organization for Standardization, Geneva, Switzerland, 1991 (revised 1999).

11. Rustemeier, K. and J.-J. Piade: Determination of nicotine in mainstream and sidestream cigarette smoke; in: Analytical determination of nicotine and related compounds and their metabolites, Elsevier, Amsterdam, 1999, pp 489-530.

12. U.S. Department of Health and Human Services: Risks associated with smoking cigarettes with low machinemeasured yields of tar and nicotine; NIH Pub. No. 025074 ed., U.S. Department of Health and Human Services, National Institutes of Health, National Cancer Institute, Bethesda, MD, October 2001.

13. Kozlowski, L.T., J.E. Hennigfield, and J. Brigham: Cigarettes, nicotine \& health; Sage Publications, Thousand Oaks, CA, 2001, pp 54-56.

14. Crooks, E.L. and D. Lynn: The measurement of intrapuff nicotine yield; Beitr. Tabakforsch. Int. 15 (1992) 75-86.

15. Kessler, D.A.: Testimony. The control and manipulation of nicotine in cigarettes; Subcommittee on Health and the Environment Committee on Energy and Commerce, U.S. House of Representatives, Washington, D.C., 1994.

16. Philip Morris USA (2003) Tobacco ingredients; 
http://www.philipmorrisusa.com/product_facts/ingredients/tobacco_ingredients.asp, accessed on 11 October 2005.

17. R.J. Reynolds (2003) Tobacco ingredients; http://www. rjrt.com/smoking/ingredientsCover.aspx, accessed on 5 January 2006.

18. Kessler, D.A., A.M. Witt, P.S. Barnett, M.R. Zeller, S.L. Natanblut, J.P. Wilkenfeld, C.C. Lorraine, L.J. Thompson, and W.B. Schultz: The Food and Drug Administration's regulation of tobacco products; New Eng. J. Med. 335 (1996) 988-994.

19. Kessler, D.A., P.S. Barnett, A.M. Witt, M.R. Zeller, J.R. Mande, and W.B. Schultz: The legal and scientific basis for FDA's assertion of jurisdiction over cigarettes and smokeless tobacco; J. Am. Med. Assoc. 277 (1997) 405-409.

20. Hurt, R.D. and C.R. Robertson: Prying open the door to the tobacco industry's secrets about nicotine; J. Am. Med. Assoc. 280 (1998) 1173-1181.

21. Pankow, J.F., B.T. Mader, L.M. Isabelle, W. Luo, A. Pavlick, and C. Liang: Conversion of nicotine in tobacco smoke to its volatile and available free-base form through the action of gaseous ammonia; Environ. Sci. Technol. 31 (1997) 2428-2433 (Additions and corrections 33 (1999) 1320).

22. Pankow, J.F.: A consideration of the role of gas/particle partitioning in the deposition of nicotine and other tobacco smoke compounds in the respiratory tract; Chem. Res. Toxicol. 14 (2001) 1465-1481.

23. Henningfield, J.E., N.L. Benowitz, G.N. Connolly, R.N. Davis, N. Gray, M.L. Myers, and M. Zeller: Reducing tobacco addiction through tobacco product regulation; Tob. Control 13 (2004) 132-135.

24. Henningfield, J.E., J.F. Pankow, and B.E. Garrett: Ammonia and other chemical base tobacco additives and cigarette nicotine delivery: Issues and research needs; Nicotine Tob. Res. 6 (2004) 199-205.

25. Bates, C., M. Jarvis, and G. Connolly (1999): Tobacco additives - cigarette engineering and nicotine addiction; Action on Smoking and Health (ASH), http://www.ash.org.uk/html/regulation/html/additives.html, accessed on 5 January 2006.

26. Willems, E.W., B. Rambali, W. Vleeming, A. Opperhuizen, and J.G.C. van Amster: Significance of ammonium compounds on nicotine exposure to cigarette smokers; Food Chem. Toxicol. 44 (2006) 678-688.

27. Saint-Jalm, Y., G. Duval, T. Conte, and I. Bonnichon: Mechanisms of transfer of ammonia in cigarette smoke from ammonium compounds in tobacco; 2000 CORESTA Congress, Lissabon, Portugal, Paper ST9.

28. Ellis, C.L., R.H. Cox, C.H. Callicutt, S.W. Laffoon, K.F. Podraza, J.I. Seeman, R.D. Kinser, D.E. Farthing, and F.H. Hsu: The effect of ingredients added to tobacco in a commercial Marlboro Lights cigarette on FTC nicotine yield, "Smoke $\mathrm{pH}$," and Cambridge filter trapping efficiency; 1999 CORESTA Meeting, Innsbruck, Paper ST 2.

29. Armitage, A.K., M. Dixon, B.E. Frost, D.C. Mariner, and N.M. Sinclair: The effect of tobacco blend additives on the retention of nicotine and solanesol in the human respiratory tract and on subsequent plasma nicotine concentrations during cigarette smoking; Chem. Res. Toxicol. 17 (2004) 537-544.

30. Callicutt, C.H., R.H. Cox, F. Hsu, R.D. Kinser, S.W. Laffoon, P. Lee, K.F. Podraza, E.B. Sanders, and J.I. Seeman: The role of ammonia in the transfer of nicotine from tobacco to mainstream smoke; Regul. Toxicol. Pharmacol., in press.

31. Dixon, M., K. Lambing, and J.I. Seeman: On the transfer of nicotine from tobacco to the smoker. A brief review of ammonia and "pH" factors; Beitr. Tabakforsch. Int. 19 (2000) 103-113.

32. Seeman, J.I.: Using "basic principles" to understand complex science: Nicotine smoke chemistry and literature analogies; J. Chem. Ed. 82 (2005) 1577-1582.

33. Lipowicz, P. and J.J. Piade: Theory and subsequent deposition of nicotine from mainstream cigarette smoke in a denuder tube; J. Aerosol Res. 35 (2004) 33-45.

34. Seeman, J.I., J.A. Fournier, J.B. Paine III, and B.E. Waymack: Thermal properties of nonprotonated and protonated nicotine. The use of thermolysis as a model for smoke formation chemistry; J. Agric. Food Chem. 47 (1999) 5133-5145.

35. Fournier, J.A., J.B. Paine III, J.I. Seeman, D.W. Armstrong, and X. Chen: Thermal mechanisms for the transfer of amines, including nicotine, to the gas phase and aerosols; Heterocycles 55 (2001) 59-74.

36. Kinser, R.D., F.H. Hsu, D.E. Farthing, L.D. Johnson, and C.L. Ellis: Nicotine collection efficiency in the FTC nicotine method; $53^{\text {rd }}$ Tobacco Science Research Conference, Montreal, Canada, Program Booklet and Abstracts Vol. 53, Paper No. 46, 1999.

37. Davies, H.M. and A. Vaught: Research cigarettes; Tobacco and Health Research Institute, University of Kentucky, Lexington, KY, 1990.

38. Parrish, M.E., J.L. Lyons-Hart, and K.H. Shafer: Puffby-puff and intrapuff analysis of cigarette smoke using infrared spectroscopy; Vibrational Spect. 27 (2001) 29-42.

39. Parrish, M.E. and C.N. Harward: Measurement of formaldehyde in a single puff of cigarette smoke using tunable diode laser infrared spectroscopy; Applied Spect. 54 (2000) 1665-1677.

40. Tang, H., G. Richards, K. Gunther, J. Crawford, M.L. Lee, E.A. Lewis, and D.J. Eatough: Determination of gas phase nicotine and 3-ethenylpyridine, and particulate phase nicotine in environmental tobacco smoke with a collection bed-capillary gas chromatography system; J. High Resol. Chromat. Chromat. Comm. 11 (1988) 775-782.

41. Ogden, M.W., K.C. Maiolo, P.R. Nelson, D.L. Heavner, and C.R. Green: Artifacts in determining the vapour-particulate phase distribution of environmental tobacco smoke nicotine; Environ. Technol. 14 (1993) 779-785.

42. Ogden, M.W. and P.R. Nelson: Detection of alkaloids in environmental tobacco smoke; in: Modern methods of plant analysis, edited by H.F. Linskens and J.F. Jackson, Springer-Verlag, Berlin, 1994, pp 163-189.

43. Ogden, M.W. and K.C. Maiolo: Comparative evaluation of diffusive and active sampling systems for determining airborne nicotine and 3-ethenylpyridine; 
Environ. Sci. Technol. 26 (1992) 1226-1234.

44. American Society for Testing and Materials: Standard test method for nicotine and 3-ethylenylpyridine in indoor air, Method No. D 5075-96; in: Annual book of ASTM standards, American Society for Testing and Materials, West Conshohoken, PA, 1996.

45. Houseman, T.H.: Studies of cigarette smoke transfer using radioisotopically labelled tobacco constituents. Part II: The transference of radioisotopically labelled nicotine to cigarette smoke; Beitr. Tabakforsch. 7 (1973) 142-147.

46. Stevens, N.A. and M.F. Borgerding: GC-AED studies of nicotine fate in a burning cigarette; Anal. Chem. 71 (1999) 2179-2185.

47. U.K. Department of Health (2001): Determination of the fate of nicotine when a cigarette is smoked, LGC Report FN40/M4/01; Smoking Policy Unit, U.K. Department of Health, http://www.advisorybodies.doh. gov.uk/scoth/technicaladvisorygroup/nicotfate.pdf, accessed on 5 January 2006.

48. Curran, J.G. Jr. and E.G. Miller Jr.: Factors influencing the elution of high-boiling components of cigarette smoke from filters; Beitr. Tabakforsch. 5 (1969) 64-70.

49. Grob, K.: Gas chromatography of cigarette smoke, part III. Separation of the overlap of gas and particulate phase by capillary columns; J. Gas Chromatog. (1965) 52-56.

50. Ceschini, P. and D. Cham: Effect of sampling conditions on the composition of the volatile phase of cigarette smoke; Beitr. Tabakforsch. 7 (1974) 294-301.

51. Keith, C.H. and J.R. Misenheimer: Vapor filtration by fibrous cigarette filters; Beitr. Tabakforsch. 3 (1966) 583-589.

52. Cochran, E.W., M.J. Joseph, S.L. Stinson, and S.S. Summers: Application of a diffusion-denuder method for the investigation of the effects of "Smoke $\mathrm{pH}$ " on vapor-phase nicotine yields from different types of cigarettes; Beitr. Tabakforsch. Int. 20 (2003) 365-372.
53. Frost, B.E., D.C. Mariner, and N.M. Sinclair: Factors relating to nicotine physio-chemistry and retention in human smokers, 1998 CORESTA Congress, Brighton, England, pp. 211-218.

54. Lewis, D.A., I. Colbeck, and D.C. Mariner: Diffusion denuder method for sampling vapor-phase nicotine in mainstream tobacco smoke; Anal. Chem. 66 (1994) 3525-3527.

55. Lewis, D.A., I. Colbeck, and D.C. Mariner: Diffusion of mainstream tobacco smoke and its effects upon the evaporation and diffusion of nicotine; J. Aerosol Sci. 26 (1995) 841-846.

56. Schmeltz, I., A. Wenger, D. Hoffmann, and T.C. Tso: Chemical studies on tobacco smoke. 63. On the fate of nicotine during pyrolysis and in a burning cigarette; J. Agric. Food Chem. 27 (1979) 602-608.

57. Watson, C.H., J. McCraw, G. Polzin, D.L. Ashley, and D. Barr: Development of a method to assess cigarette smoke intake; Environ. Sci. Technol. 38 (2004) 248-253.

Corresponding author:

R.D. Kinser

Philip Morris USA

4201 Commerce Road

Richmond, VA 23234

USA

E-mail: Robin.D.Kinser@pmusa.com 